\title{
Polycythemia vera revealed via a bladder tumor in a patient with erectile dysfunction: a case report
}

\author{
Ahmed-Amine Bouchikhi ${ }^{1,2^{*}}$, Mohammed Fadl Tazi ${ }^{1}$, Soufiane Mellas ${ }^{1}$, Driss Amiroune ${ }^{1}$, Jalal Eddine Elammari ${ }^{1}$, \\ Abdelhak Khallouk', Mohammed Jamal El Fassi ${ }^{1}$ and Moulay Hassan Farih ${ }^{1}$
}

\begin{abstract}
Introduction: Polycythemia vera is a polyglobular myeloproliferative syndrome related to the mutation of multipotent hemopoietic stem cells. This case report describes a patient whose bladder tumor was associated with polycythemia vera and erectile dysfunction. The association of bladder neoplasia with polycythemia vera and erectile dysfunction has not previously been reported in the literature.

Case presentation: A 40-year-old Moroccan man was followed up for a bladder tumor which manifested with coagulant hematuria and a facial erythrosis with a hemoglobin level of $20.3 \mathrm{~g} / \mathrm{L}$ suggesting polycythemia vera. The patient also suffered from an erectile disorder. Considering the anesthesia difficulty due to polyglobulia, the patient was treated by bleeding. This treatment enabled the patient's sexual performance to be improved and adjustment of his hemoglobin to a level allowing anesthesia, and hence surgical resection of his bladder tumor.

Conclusion: Erectile dysfunction associated with polycythemia vera is elucidated by rheological disorders. Bleeding contributed to satisfactory sexual performance and facilitated treatment of polycythemia vera because it enabled anesthesia to be performed and hence the surgical resection of the bladder tumor.
\end{abstract}

Keywords: Bladder tumor, Bleeding, Erectile disorder, Hematuria, Polycythemia vera

\section{Introduction}

Vaquez, in 1892, was the first to describe polycythemia vera [1]. Essential and acquired polyglobulia are myeloproliferative syndromes characterized by predominant clonal proliferation established in the erythroblastic lineage which is related to the mutation of multipotent hemopoietic stem cells [2].

We report the case of a patient whose bladder tumor was associated with polycythemia vera and erectile dysfunction. Considering the difficulty with anesthesia to polyglobulia, it was necessary to first treat the patient using repeated bleeding then the patient's bladder tumor by surgery. It is notable that the patient's erectile dysfunction stopped during bleeding treatment. Indeed, the association of a bladder tumor with polycythemia vera and

\footnotetext{
* Correspondence: drbouchikhi@gmail.com

'Urology Department, University Hospital of Fez, Fez, Morocco

${ }^{2}$ Rue Zag, Rce Andalous III, Quarier Al-Wafe, Fez 30070, Morocco
}

erectile dysfunction has not previously been reported in the literature.

\section{Case presentation}

A 40-year-old Moroccan man who was a chronic cigarette smoker was followed up for a bladder tumor which manifested 2 months earlier with coagulant hematuria. Resection of his bladder tumor was suggested. He reported headaches, dizziness, and a facial erythrosis. A general examination found a facial erythrosis without any peripheral adenopathy, hepatosplenomegaly, or physical masses. A clinical examination showed a middle prostate hypertrophy of $40 \mathrm{~g}$ with lower vesicle flexibility.

The preoperative biological assessment showed a hemoglobin level of $20.3 \mathrm{~g} / \mathrm{L}$, a hematocrit of $63.7 \%$, red blood cells of $6,570,000 / \mathrm{mm}$ and a hyperleucocytosis of $14,000 / \mathrm{mm}$

An arterial blood gases study and imaging examinations including thorax radiography, spirometry, renal

\section{( Biomed Central}

(c) 2013 Bouchikhi et al.; licensee BioMed Central Ltd. This is an Open Access article distributed under the terms of the Creative Commons Attribution License (http://creativecommons.org/licenses/by/2.0), which permits unrestricted use, distribution, and reproduction in any medium, provided the original work is properly cited. 
and hepatic ultrasound, thoracic and abdominal computed tomography (CT) scans, a CT scan of his brain and echocardiography showed no abnormalities. The cortisol rate of 8 hours, the urinary free cortisol, and the hemoglobin electrophoresis and markers' dosage were without abnormalities. Hence, diagnoses of secondary polyglobulia and primary neoplasia were discarded. His total globular volume was found to be higher than the normal value at a rate of $40 \mathrm{~mL} / \mathrm{kg}$ confirming the essential characteristic of this polyglobulia; the result of a JAK2 mutation test was positive.

The patient was treated using iterative bleeding. It is notable that he neither drank alcohol nor presented with any particular stress and/or depressive characteristics. His blood pressure, glycemia and lipids assessment were all normal. The vesicoprostatic ultrasound and the testicular echo-Doppler were without abnormalities.

Indeed there was a correlation between the episodes of erectile disorder and the bleeding: significant improvement of sexual performance was noted and lasted 4 days after each bleeding session. Each time the bleeding therapy was stopped the erectile disorders restarted (Figure 1).

The patient reported satisfactory sexual activity while presenting with hematuria (Figure 2). Since his marriage of one year earlier, the patient has been significantly affected by these disorders which required treatment with 5-phosphodiesterase inhibitors that unfortunately demonstrated very limited benefits.

\section{Discussion}

The association of a bladder tumor with polycythemia vera and sexual dysfunction has not previously been described in the literature. In consideration of our patient's

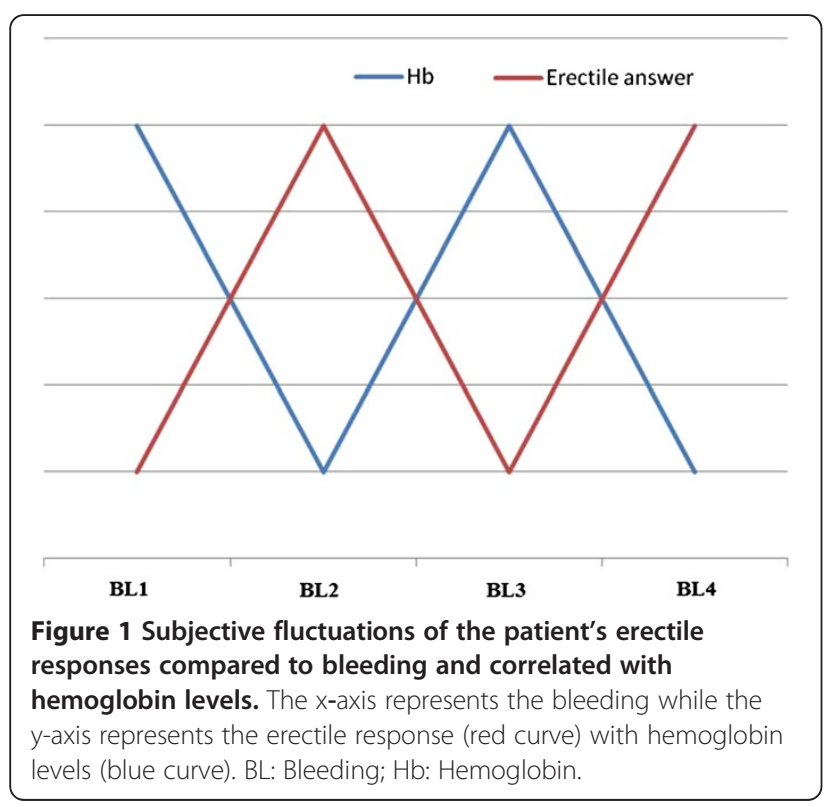

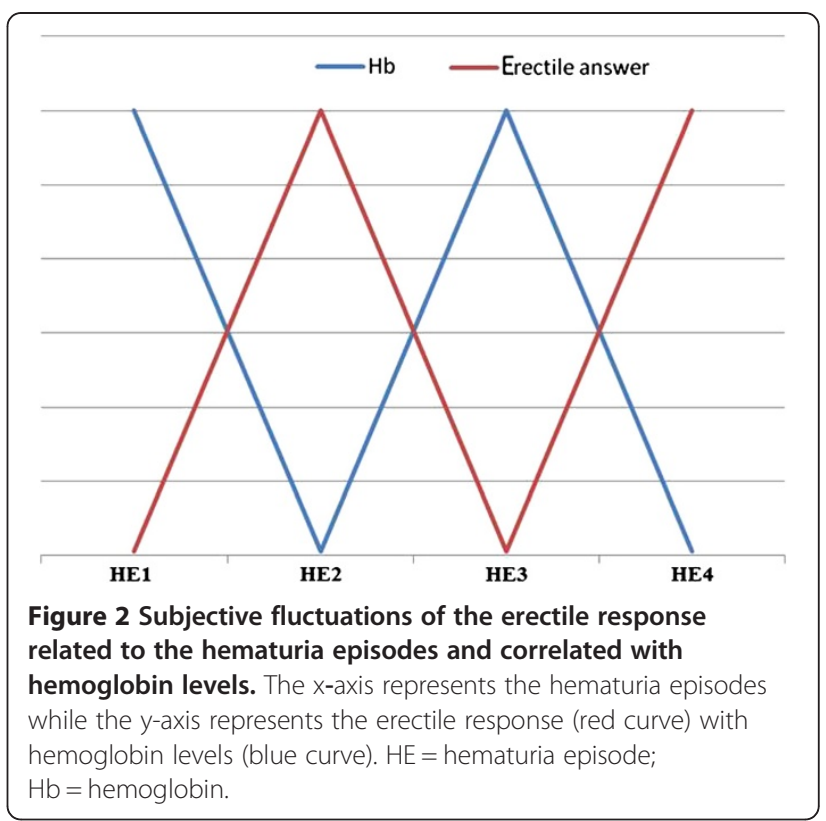

erectile dysfunction history, he was a candidate for transurethral resection of bladder tumor. The preoperative assessment allowed demonstration of the polycythemia vera diagnosis.

The difficulty with anesthesia due to polyglobulia did not allow immediate and direct surgical treatment. Hence, the patient was treated using bleeding. Indeed the patient had satisfactory sexual activity during bleeding and hematuria. Therefore, we discuss the possible mechanisms of the disorder. The occurrence of the erectile dysfunction during essential polyglobulia is explained by microthromboses; vascular thromboses are known to arise during polycythemia vera, and involve all tissue territories and could be arterial or venous [2]. Although mostly partial, the cavernous body thromboses might contribute to complicate the polycythemia vera [3-5].

The microthromboses of polycythemia vera are worsened by slow circulation, blood hyperviscosity, thrombocytosis, hypercalcemia, and intima lesions caused by turbulent circulation and hyperviscosity [6]. Besides, it is known that the ultimate stage of vasculogenic erectile dysfunction results from the occlusion of cavernous arteries. The issued polyglobulia and the hypercoagulable blood initiate anoxia which mostly affects microcirculation with a possible involvement of microthromboses and relative tissue ischemia. The bleeding quickly reduces the viscosity. Hence, it allows the main cause of the functional signs and the vascular complications of this disease [2] to be suppressed. Indeed, there is no clear evidence that demonstrates a direct relationship between polycythemia vera and erectile dysfunction. However, the bleeding was demonstrated to 
simultaneously improve the polycythemia vera and the erectile dysfunction disorders. Larger scale studies involving physiopathological aspects could clarify the direct relation that might exist between erectile dysfunction and polycythemia vera because polycythemia vera is also a vascular disease.

These arguments could explain the correlation between erectile responses and bleeding output. They constitute a good explanation of the successful sexual activity of our patient during hematuria and bleeding. It should be noted that bleeding contributed to the decrease in his hemoglobin level, which enabled anesthesia to be performed to achieve the full surgical resection of his bladder tumor. Finally, larger studies might contribute to both the clarification and demonstration of the mechanisms involved in the pathology and hence lead to better and more efficient treatment approaches.

\section{Conclusion}

Erectile dysfunction associated with polycythemia vera is elucidated by rheological disorders. Erectile disorders could originate from rheological disorders. Bleeding and hematuria allowed the patient's sexual performance to be improved and allowed opportunities for anesthesia. Hence, polycythemia vera therapy was facilitated and surgical resection of the patient's bladder tumor became possible. Larger studies may better elucidate further mechanisms of this pathology and hence lead to better treatment approaches.

\section{Consent}

Written informed consent was obtained from the patient for publication of this case report and any accompanying images. A copy of the written consent is available for review by the Editor-in-Chief of this journal.

\section{Competing interests}

The authors declare that they have no competing interests.

\section{Authors' contributions}

$A A B$ was the principal author and major contributor in writing the manuscript. MFT, SM, JEE, AK and DA analyzed and interpreted the patient data and reviewed the literature. MJE and MHF read and corrected the manuscript. All authors read and approved the final manuscript.

Received: 17 September 2012 Accepted: 8 February 2013 Published: 27 March 2013

\section{References}

1. Vaquez H: Sur une forme spéciale de cyanose s'accompagnant d'hyperglobulie excessive et persistante. C R Soc Biol 1892, 44:384.

2. Tulliez M: Polyglobulie de Vaquez. Rev Fran Lab 1997, 296:21-26.

3. Besancenot R, Pasquier F, Giraudier S: News 2011 on the pathogenesis of classical myeloproliferative syndromes (polycythemia vera, essential thrombocythemia and myelofibrosis primary). Revue Francophone des Laboratoires 2011, 433:41-46.

4. Dubois F, Lesur G, Azzouzi AR, Beurier P, Chautard D: Thrombose partielle du corps caverneux. Faut-il rechercher systématiquement une anomalie de la coagulation. Prog Urol 2007, 17:866-868.

5. Bouomrani S, Farah A, Nefoussi M, Ayadi N, Béji M: Erectile dysfunction in polycythemia vera. Presse Med 2012, 41:546-548.

6. Baruch M: Polycythemia: a review of epidemiological and clinical aspects. J Chron Dis 1965, 18:605-645.

doi:10.1186/1752-1947-7-85

Cite this article as: Bouchikhi et al: Polycythemia vera revealed via a bladder tumor in a patient with erectile dysfunction: a case report. Journal of Medical Case Reports 2013 7:85.

\section{Submit your next manuscript to BioMed Central and take full advantage of:}

- Convenient online submission

- Thorough peer review

- No space constraints or color figure charges

- Immediate publication on acceptance

- Inclusion in PubMed, CAS, Scopus and Google Scholar

- Research which is freely available for redistribution 